\section{Recreational uses might predict who's against desalination plants, and why}

Desalination plants turn saltwater from coastal resources into potable, fresh drinking water, but with high rates of energy consumption. While desalination plants can help coastal communities weather periods of drought, the high energy usage (which can contribute to more climate change, depending on the energy source) and potential direct impacts to the environment make them controversial. Desalination plants discharge concentrated saltwater (brine) which can harm marine organisms. The plants can also harm marine life that get caught in the intake pumps (fans of Sim City 2000 likely remember a running tally of surfers caught in a plant's intake).

Carlsbad only gets $16 \%$ of its water from local sources, so in 2015 , the city entered into a 30-year public-private partnership to provide more water locally via a new desalination plant. The desalination plant piggybacked off an existing power plant, getting its intake seawater from the power plant's cooling water discharge, thus not directly ingesting seawater from the ocean itself. Brine discharge from the desalination plant is also combined with cooling water discharge from the power plant to further mitigate impacts.

The adjacent man-made lagoon where these plants intake their water supply is a popular spot for recreational activities.

The authors of this study sought to find "if perceived threats to the local marine environment and marine activities influenced the degree of support for the desalination facility" in the small, coastal town of Carlsbad, California, USA. 1500 questionnaires were mailed out to random residents of the town in 2015 , with a $25 \%$ response rate. "The questionnaire included closed questions about the importance of the marine ecosystem, concerns about impacts of the plant on marine areas in California and in Carlsbad, the importance of mitigation measures to reduce impacts on marine areas, and trust in organizations to implement mitigation measures", in addition to demographic data and how often respondents engaged in marine activities.

Residents of the town were concerned about impacts on the local marine ecosystem, even on small organisms like algae and fish larvae. They were also concerned about impacts on their recreational activities, like shellfish harvesting and fishing. All questions related to reducing impacts of brine discharge were highly rated, with more emphasis placed by residents on avoiding impacts than offsetting them. Residents were more trustful of Federal regulators like NOAA and EPA than California's State Water Resources Control Board.

"Linear regression analysis revealed that ocean use was a significant predictor for placing high importance on marine features and for high concerns about impacts to the marine environment and marine activities". Demographic data was less helpful at indicating support. Nonconsumptive behaviours correlated with placing higher importance in the local marine ecosystem and impacts that would affect these nonconsumptive uses. Fishers, on the other hand, were mostly concerned about impacts on fishing. Fishing was also "negatively correlated with institutional trust in federal and state governmental agencies" while the nonconsumptive user group placed more emphasis on management measures to reduce impacts.

This research shows us that while both consumptive and consumptive user groups opposed the desalination plant, they did so for different reasons: recreational users did
This is a summary of: Management preferences and attitudes regarding environmental impacts from seawater desalination: Insights from a small coastal community

Accessible at:

https://marxiv.org/k47da

Authors: Nadine Heck, Adina Paytan, Donald C. Potts, Brent Haddad, Karen Lykkebo Petersen

Added to MarXiv: June 2018

Published: Ocean \& Coastal Management, 2018

Suggested Citation: Recreational uses might predict who's against desalination plants, and why. OCTO (2018). DOI: 10.31230/osf.io/tmwbn

See more MarXiv summaries at https://www.marxivinfo.org/ summaries

Share your research in MarXiv and the MarXiv Team may summarize it, just like this!

Step-by-step instructions on how to share your research in MarXiv are detailed at https://www.marxivinfo.org/ submission

Across all disciplines, papers available for free with a preprint (also known as "Green OA") are cited $30 \%$ more than the world average (DOI: 10.7287/peerj. preprints.3119v1) 


\section{MarXiv Summary}

MarXiv: The free research repository for the ocean \& marine-climate sciences

not trust the operators of the plant and were concerned about negative impacts, whereas fishers did not trust the relevant agencies to manage impacts.

\section{MarXiv}

The MarXiv Team

Nick Wehner,

Director of Open Initiatives,

OCTO

Raye Evrard,

Project Manager, Осто

Allie Brown,

Project Associate, Осто

Sarah Carr,

Chief Knowledge Broker,

OCTO

John Davis,

President, OCTO

Correspondence

Nick Wehner

nick@octogroup.org

Financial support for MarXiv comes from the David and Lucile Packard Foundation.

The views expressed herein are those of the MarXiv Team and should not be interpreted as representing the opinions or policies of the Packard Foundation or other funders of MarXiv.

Join the MarXiv Summaries monthly newsletter at https:// oct.to/marxivsum

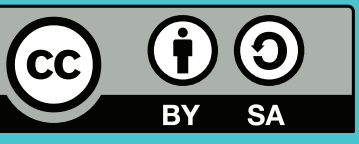

MarXiv is an ОСТO Initiative
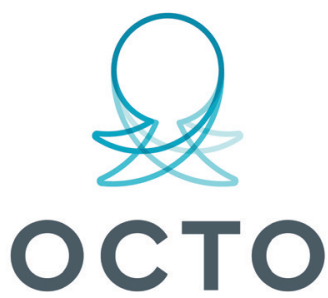

OPEN COMMUNICATIONS FOR THE OCEAN 